Erstes Treffen des neu gewählten FVDZ-Bundesvorstandes

\title{
Weichen für die nächsten zwei Jahre gestellt
}

Knapp 14 Tage nach der Wahl-Hauptversammlung in Bonn traf sich der neu gewählte Bundesvorstand des Freien Verbandes Deutscher Zahnärzte (FVDZ) in Berlin zu seiner ersten Sitzung. Das Team um den neuen Bundesvorsitzenden Harald Schrader stellte an dem Oktoberwochenende die Weichen für die Verbandsarbeit in den nächsten zwei Jahren.

Schwerpunkte der zweitägigen, arbeitsintensiven Sitzung waren standespolitische Themen, wie die zahnmedizinische Versorgung in ländlichen Regionen, die Behandlung von Flüchtlingen, Asylbewerbern und Migranten sowie das zukünftige Verhältnis zu den Körperschaften. Gesundheitspolitische Themen sollen in Zukunft wieder mehr in den Vordergrund der Verbandsarbeit rücken, wie Harald Schrader zu Beginn der Tagung erklärte. So sieht der neue Bundesvorstand eine Hauptaufgabe darin, die schon bestehenden und zukünftig verstärkt drohenden Wettbewerbsverzerrungen, die die Berufsausübung in den freien Praxen der Niedergelassenen betreffen, zu beseitigen und fai- re Wettbewerbsbedingungen für die Praxen im teilregulierten Gesundheitsmarkt zu schaffen.

Der Kampf wird sich vor allem auch gegen die überbordende Bürokratie - wie sie gerade erst durch den Normenkontrollrat dokumentiert worden ist - aus Brüssel und Berlin richten. Überzogenen Anforderungen bei der Berufsausübung, wie sie bereits heute bestehen, erteilte der Bundesvorsitzende eine klare Absage.

Für die Sitzung des erweiterten Vorstandes im Dezember in Stuttgart wurden drei Arbeitsgruppen gebildet: 1. Thema: Versorgung in ländlichen Regionen, 2. Thema: Flüchtlingspolitik, 3. Thema: Mehrleistungsfähigkeit der BEMA-Leistungen. pk

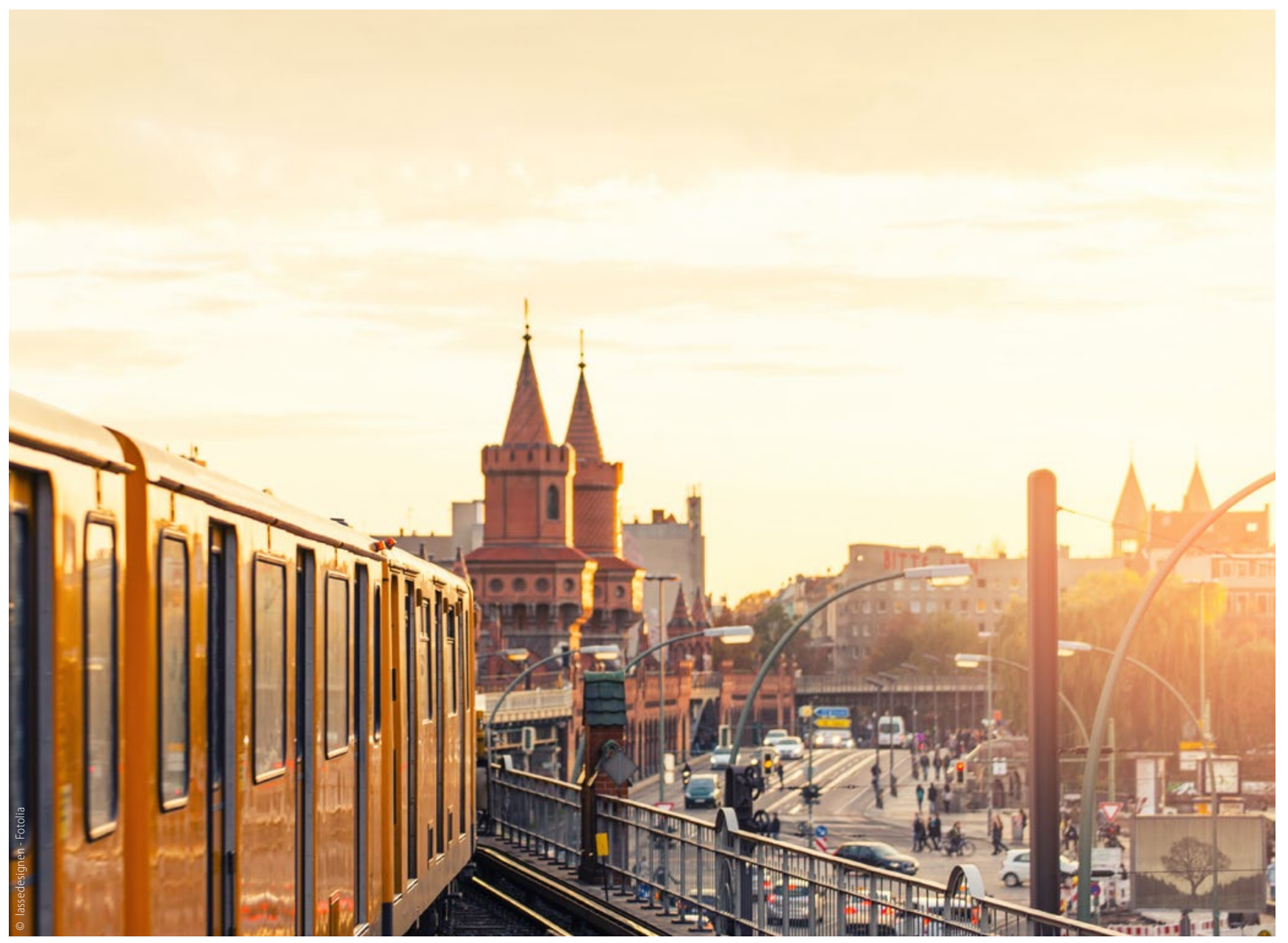

